\title{
PABLO NERUDA Y LA SOLIDARIDAD ARTÍSTICA
}

\section{Pablo Neruda and artistic solidarity}

\section{Carlos Trujillo*}

Mucho se ha escrito y se sigue escribiendo acerca de la obra poética y la importancia política del chileno y Premio Nobel de Literatura 1971, Pablo Neruda. Por tanto, dificil o poco menos que imposible es dar con una obra o parte de su obra escrita que no haya sido comentada, criticada, estudiada y traducida a los más diversos idiomas. Igualmente, la figura pública del poeta así como su participación en la vida política de Chile y Latinoamérica han sido no solo estudiadas, analizadas y examinadas con el máximo rigor por estudiosos de reconocido prestigio sino que también han sido representadas y recreadas incluso en obras de ficción. Sin embargo, el volumen de la obra nerudiana y su trayectoria como poeta y lector es tan grande y abarcadora que siempre es posible encontrar algún tema que haya sido menos estudiado por la academia y aún menos conocido por el lector común.

Hurgando en la magnífica edición de sus Obras Completas, preparada por Hernán Loyola, y publicada por Galaxia Gutenberg (Neruda, 2001a), al mismo tiempo en que hacía la última revisión de un manuscrito de la importante colaboración del poeta a un estadounidense que realizó un proyecto fotográfico en Chiloé, Chile, en 1967, pude comprobar que aunque otros han tratado el tema de la solidaridad de nuestro Premio Nobel, su mirada siempre se ha limitado a lo que podría llamar la solidaridad grande o prestigiosa, es decir, aquella de fuerte connotación política y social que, por tocar a un gran grupo de personas, a un pueblo entero o a una colectividad política, trasciende de inmediato y se vuelve reconocida y elogiada por todos.

Por lo mismo, es fácil dar con estudios minuciosos o breves notas concernientes a la solidaridad de Neruda con el pueblo español durante los trágicos años de la guerra civil. Al respecto, como afirma Rovira Soler (s/f), "un recorrido sobre el tiempo de la solidaridad en aquella guerra nos puede abrir como reflexión una marca nueva en su poesía que determinó una transformación poética de la misma". Totalmente cierto lo que plantea Rovira Soler y, por tal razón, abundan los estudios respecto de ese tema.

Y si se quiere ser más específico en una acción individual que muestre de cuerpo entero la solidaridad y el compromiso social y político de Neruda en ese tiempo, basta recordar su tarea para conseguir y preparar el viaje del carguero Winnipeg "que desde Pauillac (Burdeos) trasladó a Chile el 4 de agosto de 1939 a más de 2.000 españoles, hacinados y hambrientos hasta entonces en los campos de concentración franceses que sirvieron de inhóspito refugio a la diáspora de casi medio millón de personas que cruzó la frontera huyendo de la represión franquista". Según informa una reseña de la película documental "La travesía solidaria", de Dominique Gautier y Jean Ortiz, patrocinada por el Canal 3 de la televisión pública francesa. 


\section{Carlos Trujillo}

Dadas mis razones, este ensayo tratará acerca de actos de solidaridad mucho más pequeños y, por lo mismo, intrascendentes para el gran público y para los estudiosos de su obra, pero no por eso menos importantes en su momento para aquellas personas a las que fueron dirigidos.

El mismo Neruda, unido a la tradicional imagen del poeta como un ser que se mira a sí mismo y observa o recrea el mundo desde su muy particular y privada posición, también ha servido para ocultar la solidaridad pequeña, por así llamarla. Esos hechos realizados no por un afán de servicio público o general, sino muestras de afecto, fraternidad y apoyo a otro igual o semejante a él para quien su ayuda, por pequeña que fuera, se transformaría en un empujón impagable. Tal vez el propio Neruda ayudó a que sus lectores tuvieran de él la imagen de un poeta preocupado solo de sí mismo. Si no de qué manera se entenderían versos como "Yo me río, / me sonrío / de los viejos poetas, / yo adoro toda / la poesía escrita, / todo el rocío, / luna, diamante, gota / de plata sumergida, / que fue mi antiguo hermano, / agregando a la rosa, / pero / me sonrío / siempre dicen 'yo' / a cada paso / les sucede algo, / es siempre 'yo', / por las calles / sólo ellos andan / o la dulce que aman, / nadie más..." Es claro que este poema que abre sus Odas elementales en 1954, no solo se refiere a los otros poetas sino a él mismo o, por lo menos, al poeta que fue o que había sido hasta entonces.

$\mathrm{Y}$ es totalmente válido pensar que Neruda, como poeta y como la gran figura del mundo literario chileno de su tiempo, nunca haya dejado de mirarse el ombligo. Sin embargo, junto con el poeta maduro o al muchachito sureño que a fines de la segunda década del siglo XX intentaba crear su propio camino en la poesía, siempre estuvo presente el ser humano observador, generoso, fraternal, dispuesto a ofrecer una mano a sus amigos y a otros que llegaran a serlo por el solo hecho de ir caminando por las mismas vías de la poesía y del arte.

\section{NERUDA ANTES DE NERUDA}

El volumen IV de sus Obras Completas (Neruda, 2001b), subtitulado Nerudiana dispersa I, que abarca varios escritos de 1915 a 1964 nos ofrece una extensa serie de prólogos, catálogos, reseñas, notas y otros textos que el poeta escribió para mostrar, difundir y promover las creaciones de otros autores (poetas, novelistas, pintores) de su tiempo, algunos de ellos de escasa figuración y mínima trascendencia, pero que el poeta con una generosidad bastante escasa en el campo de las artes, consideró que necesitaban un empujoncito de aliento para llegar a su público y que él estaba dispuesto a dárselos.

No se piense que estas muestras de talento crítico y de humanísima generosidad surgieron en él en sus años de madurez o que comenzó a realizar esta labor cuando ya era un poeta hecho y derecho y una voz de peso en el panorama literario y artístico nacional. Tampoco se piense que eso habría significado una gran diferencia temporal, ya que sus Veinte poemas de amor y una canción desesperada que lo transformaron en el poeta más leído de Chile en los años siguientes a su publicación, apareció editado por primera vez en 1924, cuando el poeta recién cumplía veinte años de edad. Tampoco hay que olvidar que 
un año antes ya había publicado su inicial Crepusculario, que entre sus muchos poemas contiene el famosísimo Farewell que, según el propio Neruda, era uno de los poemas favoritos para recitar tanto en los grandes salones de la sociedad como en los prostíbulos de nuestra larga patria. Pero no fue en 1923, ni tuvo que esperar hasta su llegada a Santiago ni el inicio de sus estudios nunca acabados de Pedagogía en Francés, cuando el jovencísimo poeta tuvo la generosa iniciativa de mostrar a los lectores de la prensa temuquense y santiaguina el trabajo de sus coetáneos, de otros muchachos tan jóvenes y tan desconocidos como él, para que otros ojos y otras mentes se enteraran de su existencia y valoraran esos talentos. Para que se enteraran todos los que leyeran sus notas y reseñas que había jóvenes creando, entregando sus poemas, cuentos, novelas, pinturas y revistas a un público que los desconocía por completo.

Ya en su edición de septiembre-octubre de 1921, la revista Juventud (Santiago) publicó un poema suyo titulado "A los poetas de Chile." En dicho poema el joven estudiante hacía un llamado a todos los poetas de la patria para que levantaran su voz contra la injusticia del apresamiento de Joaquín Cifuentes Sepúlveda, llamando a los jueces a dar la libertad a su amigo poeta, conocido en la bohemia santiaguina como "El Ratón Agudo". ¿Qué edad tenía entonces Pablo Neruda? Nada más que diecisiete años. Y estaba empezando a cursar su primer año en la universidad. No sé si este sea uno de sus primeros textos políticos, pero no hay duda que en él es evidente su compromiso con la justicia y con sus pares.

Pero no se quedan ni empiezan allí las muestras de solidaridad y generosidad del joven poeta, que el 30 de septiembre de 1919, cuando solo contaba con quince años y asistía a ese liceo que hoy lleva su nombre, allá en las faldas del Nielol, había publicado en el diario La Mañana, de Temuco, una nota titulada "La exposición Oyarce", en la que ni siquiera sus cortos años logran impedir su deseo de entregar una crítica tan objetiva como le fuera posible del trabajo de su amigo: "Indudablemente tiene aciertos, dibujos que son una demostración de su capacidad artística, dibujos que ejecutados bajo la influencia directa de Valenzuela y Meléndez, nuestros dibujantes de avanzada, tienen mucho de acabada perfección; pero hay otros que nos dan inmediatamente la sensación de mal gusto, de extremada confusión en las imágenes y de errores indudables en la técnica" (Neruda, 2001b, p. 245).

El 29 de diciembre de 1919 ese muchachito de tan solo quince años de edad llega a los lectores de La Mañana con una nota titulada "“Y dolor, dolor, dolor...' poemas de F. García Oldini”. ¿Quién sabe hoy quién fue aquel Fernando García Oldini? Y, de verdad, poco importa saber quién fue, cuando lo verdaderamente importante en este caso es el reconocimiento de un valor extraordinario y siempre presente en la vida de Neruda desde su más tierna adolescencia hasta sus días finales, ya transformado en un ícono vivo de la poesía y la cultura chilena y latinoamericana: su generosidad a toda prueba.

¿Qué es lo que dice el joven Neftalí de tal libro? Nada más ni nada menos que lo que cito más abajo casi en su totalidad: 
Ha sido latido recio, hondo de emociones inhalladas el que me sorprendió en la lectura de este libro. Pasan por sus poemas las filtraciones venenosas del dolor y de la duda en un desgajamiento de musicalidades firmes y vibrantes, a veces inundadas por la fiebre de la sensualidad o de la obsesión, pero hechas quizás en qué divinos torrentes de luz, plasmadas en admirables gritos líricos. Me he acordado amargamente de algunos seudocríticos que sin comprender el inmenso pedazo de belleza que se abre en este libro, lo han ridiculizado estúpidamente.

Y después de haber leído esos trozos en que hasta se ha llegado a deformar y agregar palabras ridiculizantes a los versos de García Oldini, he vuelto a leer serenamente el libro.

Pero ha sido la misma sensación única, he sentido de nuevo este mismo aroma hecho de espasmos de dolor o duda que vibra en todos los poemas, que se hace suavidades de seda dolorosa en la "Sinfonía desolada" y asperezas de tierra sensitiva y humana en los "Versos de la fiebre".

Como dijo González Vera, estos versos no se parecen a los de ningún otro poeta. Y porque son únicos, y porque están tan hondamente ungidos en los ritos estrujantes del dolor, llegan y aletean adentro de nosotros y vibran, y vibran... (Neruda 2001b, p. 245-47).

Pecará de exigente quien quiera encontrar en esta reseña escrita por Neftalí Reyes una palabra propia y consolidada, y más aún quien quiera ver en este texto el pensamiento de un crítico literario, ávido navegante de océanos de teorías. Nada de eso debe buscarse en esta emotiva reseña escrita por el jovencísimo poeta, pero esto no significa que no encontremos en su texto buenas muestras de lo que era su escritura de esos días, de sus influencias más marcadas en ese momento, y de su deseo de promover a los demás poetas que por entonces habitaban ese pequeño trozo de mundo.

El 27 de abril de 1920 publica una nota titulada "Un recuerdo de Selva austral: E. Silva Román". En esos días, Ernesto Silva Román era un joven avecindado en Temuco donde durante algunos años había estado ganándose la vida en labores periodísticas en ese mismo medio de prensa. Selva austral, por otro lado, no era el título de un poemario ni de una novela sino una revista literaria. El joven Neftalí -por esos días Presidente del Ateneo Literario del Liceo de Temuco- parece conocer muy bien las dificultades de los jóvenes escritores para conseguir apoyo de la comunidad, e informa - en lo que suena a una emotiva denuncia- que el fracaso del sueño editorial de su amigo lo ha llevado no solo a abandonar su empresa sino también a alejarse de esa pequeña ciudad tan falta de talentos como el del propio Silva Román.

Veamos parte de su nota:

Has leído los versos de Silva Román en “Siembra”? Sí, muy buenos.

Y me he quedado pensando en aquel gran muchacho de los ojos profundos que vivió tres años en este pueblo, desconocido de casi todos, haciendo versos extraños e ilusiones sencillas. Se aburrió. Su espíritu claro de aventurero joven se adormecía en el soberbio quiste de este pueblo. Y un día, sin decirnos adiós apenas, se fue...

Pero antes había sido un héroe. Había logrado mantener una revista. Y medios! Mantener una revista aquí es un acto heroico. Es encararse con gente egoísta, es 
ponerse frente a hombres absurdos, frente a pequeños odios sin razón, a tantas cosas (Neruda, 2001b, p. 250-251).

El primer logro del joven Neftalí es el de organizar su comentario como si fuera una conversación con un interlocutor anónimo, lo que con toda seguridad habrá conseguido lectores que sin ningún interés por los temas literarios o artísticos, habrán 'picado' gracias al anzuelo del aparente diálogo. ¿Qué es lo que se comenta aquí? Apenas iniciado su texto presenta al personaje y el hecho que quiere denunciar: el incipiente pueblo de Temuco parece no estar preparado ni abierto para recibir "jóvenes de espíritu claro y aventurero", de modo que los 'heroicos soñadores' que intentan darle vuelo al pensamiento y a la palabra escrita deben alejarse de allí en busca de otras tierras donde tal vez haya menos 'gente egoísta', menos 'hombres absurdos' y menos 'odios sin razón'.

Nadie negará la audacia ni la desfachatez del muchachito que a los dieciséis años levanta críticas tan fuertes a los grupos dominantes de su ciudad. Sus dieciséis años de edad, sus grandes sueños y el recargadísimo lenguaje del romanticismo imperante en la época (gran muchacho de los ojos profundos; versos extraños e ilusiones sencillas; espiritu claro de aventurero joven; héroe, etcétera) se unen perfectamente en este breve párrafo para otorgarle mayor énfasis a su denuncia.

\section{EL JOVEN POETA EN SANTIAGO}

Imaginamos cómo le cambiaría el mundo -la visión de mundo- a un muchacho provinciano de pueblo pequeño y fronterizo, de principios del siglo XX, su llegada a la ciudad capital del país. Llegar, acomodarse, matricularse en la universidad, iniciar amistades con sus pares de ese mundo distinto, más liberal, más variado, y donde todo parece moverse con una prisa inusitada. Mucho debe haber influido en nuestro joven poeta el encuentro con ese nuevo mundo, con la universidad, con otros escritores, artistas e intelectuales tan jóvenes como él.

Lo cierto es que desde su llegada a la capital se integra a ese medio no como uno del montón sino que empujando firme para para convertirse en el centro de ese grupo de jóvenes intelectuales, soñadores y bohemios. Hasta donde se sabe, Manuel Rojas (18961973), autor de novelas señeras como Hijo de ladrón, Mejor que el vino y Sombras contra el muro, igual que muchos otros se inició en la escritura mediante la poesía. Asimismo, al revisar su bibliografía encontramos que en el lapso de su vida publicó solo dos poemarios en Chile, Tonada del Transeúnte (1927) y Deshecha Rosa (1954). Sin embargo, Pablo Neruda, ya firmando con ese nombre, publicó una brevísima nota titulada "Manuel Rojas" en el número 15 de la Revista Juventud, en agosto de 1921. La minúscula nota dice lo siguiente: "Noble serenidad del verso de Manuel Rojas. Parece que brotara desde el fondo mismo de un alma macerada en la belleza, sabia en exprimir de sí misma un divino y puro licor de poesía" (p. 251) La brevedad es telegráfica, pero no dudamos que la descripción que hace de esa poesía debe haber sido un fuerte y emotivo espaldarazo para Rojas que hasta entonces había publicado solo un soneto ("El gusano") en la Revista Los Diez (1917), y un conjunto de poesías bajo el título de Poéticas, en la Revista Ideas y 


\section{Carlos Trujillo}

Figuras, de Mendoza, Argentina, de 1921, que deben ser los poemas a los que se refiere este comentario.

Es evidente que el joven Neruda no temía a los críticos ni a la crítica ni tampoco temía -o no le importaba- equivocarse. Dar sus juicios y opiniones acerca de sus coetáneos no solo le resultaba natural sino que hasta hace ver que le parecía una tarea ineludible informar por la prensa respecto de las publicaciones de otros escritores, opinar de ellas e incitar a su lectura. Ese interés de mostrar a sus coetáneos y de promover su lectura debe entenderse no solo como su deseo natural de opinar y de ir depurando su talento crítico, sino más que nada como una muestra enorme de su solidaridad con los otros escritores y artistas.

\section{NOTA SOBRE PABLO DE ROKHA}

El sitio de internet http://www.memoriachilena.cl/ dedicado al poemario Los Gemidos de Pablo de Rokha informa lo siguiente de la recepción que dicho libro tuvo entre algunos connotados críticos de la época: "Cuando Pablo de Rokha publicó Los Gemidos en 1922, Alone (Hernán Díaz Arrieta) señaló: "Su libro Los Gemidos constituye uno de los documentos de la literatura patológica aparecidos después de la guerra en los países no afectados por este fenómeno de un modo directo". En tanto, Raúl Silva Castro agregó: "Se puede advertir la substancial vulgaridad de sus expresiones y la exageración del mal gusto y la retórica puerilmente conducida hasta el ofuscamiento del lector".

Neruda, entretanto, restó importancia a las opiniones de tan altas autoridades críticas del medio santiaguino, y escribió la suya que no solo se opone a aquellas sino que las refuta por completo:

Un impulso hacia la raíz trascendente del hecho, una mirada que escarba y agujerea el esqueleto de la vida y un lenguaje humano, de hijo de mujer, un lenguaje exacerbado, casi siempre sabio, de hombre que grita, que gime, que aúlla, esa es la superficie de Los gemidos. Más adentro, libres ya de las palabras, de los alaridos, y de las blasfemias, sentimos un amador de la vida y de las vidas, azotado por la furia del tiempo, por los límites de las cosas, corroído hasta la médula por la voluntad de querer y por la horrible tristeza de conocer. Continuador del coro trágico? Tal vez. Lejos de la ataraxia de los socráticos, P. de R. trasluce su sentido de la vida, en una agitación discontinua, que se paraleliza a la de los cantores de Dionysos. Canta a Prometeo, griego de nacimiento, cuando desata su imprecación al católico Satanás. Y su libro entero es un solo canto, canto de vendaval en marcha que hace caminar con él a las flores y a los excrementos, a la belleza, al tiempo, al dolor, a todas las cosas del mundo, en una desigual caminata hacia un desconocido Nadir (Neruda, 2001b, p. 267).

Notable reseña del joven Neruda, que oponiéndose a la crítica con anteojeras de las autoridades máximas de la crítica nacional de ese momento, da cuenta no solo de la certeza de sus convicciones estéticas sino que se adelanta en muchos años a lo que será al juicio crítico que reciba esa obra considerada hoy una de las obras fundamentales de la 
vanguardia hispanoamericana. Además, notable acto de coraje del poeta llegado solo un año antes a la capital y de solidaridad con un poeta de esos días.

\section{PRÓLOGOS Y OTROS ESCRITOS}

Largo sería enumerar los prólogos y otros textos nerudianos motivados por la amistad, la solidaridad y el compromiso con sus pares, así como con sus amigos y amigas. En algunos primará una de las razones por sobre las demás; en otros, las tres en conjunto parecieran ser la motivación de sus escritos.

Al revisar la totalidad de sus textos prologales y reseñas no nos queda duda de que al poeta se le hacía muy difícil negarse a escribir unas letras a quien se lo pidiera, sin importar si fuera alguien muy cercano a él o simplemente un recién conocido que le puso en el aprieto de reseñarle o prologarle un libro. Ciertamente no se extendió ni profundizó de igual manera en el comentario de las obras de todos sus solicitantes, pero pareciera que generalmente cumplió la tarea solicitada y, tal vez, eso mismo incentivó a otros a pedirle que comentara sus textos.

Por ejemplo, llama muchísimo la atención su telegráfico comentario de un libro titulado Serenamente, de Fernando Mirto, del que apenas dice: "Entiendo que está comenzando" (Neruda, 2001b, p. 316). Sospechamos que este debe ser el más breve de sus comentarios publicados.

No mucho más extenso es el que dedica a El silbar del payaso, del poeta peruano Mario Chávez, publicado en el mismo número y misma página de Claridad: "Verso ansioso de nuevas formas pero atrozmente descolorido y sin tormento. No me gusta". (Neruda, 2001b, p. 316). Hay otros, sin embargo, en que el compromiso con el amigo es evidente, como por ejemplo su nota-prólogo para el libro Canción de amor para tu sueño de paz, de Práxedes Urrutia (Neruda, 2001b, p. 994), primer poemario de la tercera esposa de su gran amigo Rubén Azócar.

Sin embargo, me atrevo a asegurar que gran parte de las reseñas, prólogos y textos dedicados a sus amigos y amigas fueron motivados por su admiración y reconocimiento al texto, a la obra en general o a la figura de la persona en cuestión. Basten para demostrarlo sus "Notas sobre la poesía de Juvencio Valle", El Mercurio, 20 de noviembre de 1932; sus Palabras para Alejandro Lipzchütz, en El Siglo, 19 de agosto de 1944; su prólogo a Carbón, de Diego Muñoz, Santiago, Editora Austral, 1953, que comienza: "Creo que Diego Muñoz es el escritor más interesante de Chile. Hay en nuestra pequeña literatura figuras majestuosas o singulares, pero ningún revelador como Diego Muñoz" (Neruda, 2001b, p. 895-897). Igualmente, su prólogo a La piedra del pueblo, segundo libro de Efraín Barquero, Santiago, Editorial Alfa, 1954, en el que leemos: "La poesía de Efraín Barquero tiene cuerpo. Es un material rico, una reconstrucción según las leyes de la vida, con palabras, con frases que parecían inútiles y que a su reclamo vuelven a brillar como espadas, relucen como el vino, se transforman en piedras, elevan otra vez la dignidad del canto" (Neruda, 2001b, p. 962). 
Párrafo aparte merece la Nota-prólogo a Nicanor Parra, que sirviera de prólogo a la primera edición de Poemas y antipoemas (1954). Mirado desde la perspectiva de hoy, cuando Nicanor Parra es no solo la mayor figura viva de las letras nacionales sino uno de los poetas imprescindibles del mundo hispano, podría parecer que este texto no amerita el calificativo de solidario ni mucho menos que significarán un empujón a la "carrera" del antipoeta. Sin embargo, parodiando al propio Parra habría que decir que en 1954 eran otros los gallos que cantaban. Hasta entonces, Nicanor Parra solo había publicado Cancionero sin nombre, diecisiete años antes $\mathrm{y}$, basándose en ese único libro, era dificil imaginar la importancia que llegaría a tener y la influencia que llegaría a ejercer en varias generaciones de poetas de América y España. Nadie podrá decir que las palabras prologales de Neruda hayan dado con la definición exacta de lo que estaba proponiendo el antipoeta, pero igualmente nadie podrá negar el espaldarazo que debió significar para el todavía joven Nicanor ese breve prólogo que empieza con la siguiente afirmación: "Entre todos los poetas del sur de América, poetas extremadamente terrestres, la poesía versátil de Nicanor Parra se destaca por su follaje singular y sus fuertes raíces" (Neruda, 2001, p. 913).

Sin embargo, tal vez la más grande muestra de admiración de Pablo Neruda a un intelectual y gran amigo suyo sea la que encontramos en el extenso prólogo a El problema racial en la conquista de América y el mestizaje (1963), de Alejandro Lipschütz, que entre otras cosas dice:

El hombre más importante de mi país no mandó nunca regimientos, no ejerció nunca un ministerio, no mandó, sino que fue mandado en una universidad de provincia. Sin embargo, para nuestra conciencia, él es un general del pensamiento, un ministro de la creación nacional, el rector de la universidad del porvenir. El más universal de los chilenos nació lejos de estas tierras, de estas gentes, de estas cordilleras. Pero nos ha enseñado más que millones de los que aquí nacieron: nos ha enseñado no solo ciencia universal, método sistemático, disciplina de la inteligencia, devoción por la paz. Nos ha enseñado la verdad de nuestro origen mostrándonos el camino nacional de la conciencia (Neruda, 2001, p. 1189).

\section{PARA MUESTRA, UN BOTÓN}

En el verano estadounidense de 1966, el fotógrafo Milton Rogovin le envió una carta a Pablo Neruda en la que, luego de tres párrafos introductorios, le decía lo siguiente: "Me gustaría pedirle su consejo y ayuda en relación a un proyecto fotográfico que tengo en mente. Me gustaría ir a Chile por unos cuantos meses y fotografiar la vida de un pueblo pequeño. Indudablemente usted conoce muchos pueblos que podrían ser adecuados. Pero sobre todo, si usted encontrara satisfactorio mi trabajo, ¿le importaría escribir algo para ir con mis fotos?".

Hasta ese momento el poeta chileno nada sabía del fotógrafo, cuyo trabajo empezó a conocer precisamente mediante esa carta y el material recibido. Sin embargo, ese escaso conocimiento del compañero artista no impidió que le respondiera el 13 de noviembre de 
1966, incentivándolo a realizar su viaje y su proyecto fotográfico y ofreciéndole toda su cooperación, según vemos en el texto de su carta escrita originalmente en inglés :

Querido amigo,

Su trabajo es maravilloso y yo me sentiré gratamente honrado de colaborarle en cualquier empresa.

Dos cosas: (1) ¿Qué época del año es la mejor para su viaje a Chile? Yo nunca estoy seguro de mi estabilidad en un lugar, nunca sé cuándo tendré que viajar. Es importante fijar las fechas. Ahora es primavera aquí. Invierno, Junio y Julio. (2) Chile tiene el desierto en el Norte, viñas y ciudades en el Centro, lluvia y frío en el Sur, el cual llega hasta la antártica. Hay rebaños de Ovejas hasta el Estrecho de Magallanes y la Antártica.

Hay una isla grande: Chiloé, lejos en el Sur. Yo creo que ése será [el lugar elegido]. Está maravillosamente intacta; es pobre y llena de interés humano. ¿Yo podría ir con usted este verano, Enero, Febrero 1967 o el próximo verano de 1968 ?

Cuénteme todo sobre sus posibilidades y sepa que aquí tiene a un amigo.

Sinceramente

Pablo Neruda

Imaginamos cómo habrá sorprendido esta respuesta al fotógrafo norteamericano ${ }^{2}$. El poeta chileno Pablo Neruda en la cúspide de su fama no solo se mostraba "gratamente honrado de colaborarle en cualquier empresa" sino que también le indicaba el lugar donde debería desarrollar su serie fotográfica y deslizaba la posibilidad de acompañarlo a Chiloé, ya fuera en el verano de 1967 o en el de 1968.

A no dudarlo, la impresión que le causó tan amistosa respuesta hizo que Milton Rogovin no entrara en mucho detalle al leer que el poeta podría acompañarlo (con toda la condicionalidad que ofrece dicha forma verbal) en "Enero, Febrero 1967 o el próximo Verano de 1968". Es evidente que Neruda manifiesta su característica generosidad, pero, de acuerdo con el texto, no parece percatarse de que haya gran urgencia en la realización del viaje. Igualmente, el fotógrafo no se da ni por enterado de la advertencia de Neruda: "Yo nunca estoy seguro de mi estabilidad en un lugar, nunca sé cuándo tendré que viajar. Es importante fijar las fechas. Ahora es Primavera aquí. Invierno, Junio y Julio". De acuerdo con los documentos, Rogovin recibió la respuesta del poeta a fines de noviembre de 1966, puesto que el 30 del mismo mes le escribe su segunda carta a Neruda en la que da por hecho que viajará cuanto antes y que el poeta lo acompañará en su viaje al sur (“¿Estaremos quedándonos en un lugar fijo o estaremos viajando?”. “¿Cómo iremos a las distintas áreas de Chiloé? El equipo de trabajo que lleve dependerá de los medios de transporte $[. .$.$] ¿Cuándo y dónde me encontraré con usted?"), a la vez que demuestra un$

\footnotetext{
${ }^{1}$ La traducción al español es mía y fue publicada en Nada queda atrás. En adelante no se volverá a hacer la indicación, pero cada texto o traducción de textos de Neruda o Rogovin fue hecha por mí.

${ }^{2}$ En su Autobiografía expresa lo siguiente: "A menudo me sorprende cómo tuve el coraje de contactar a Pablo Neruda y preguntarle si podría colaborar conmigo en un proyecto que haríamos en Chile. Ocasionalmente leía poemas de Neruda en la prensa radical y me enteré de que él había colaborado con un buen número de artistas" (Rogovin, s/f, p. 43). La traducción es mía.
} 


\section{Carlos Trujillo}

total desconocimiento de la manera en que llegará a Chile ("La mayoría de los aviones de aquí van a Santiago ${ }^{3}$. Yo puedo cambiar de avión en Lima e ir de allí a Valparaíso").

Estos datos revelan la urgencia de Rogovin para realizar su serie fotográfica y, muy especialmente, contar con la colaboración del poeta chileno. Por desgracia, no se preocupó del aviso que el poeta nunca estaba seguro de su estabilidad en un lugar, ni menos de otros hechos igualmente importantes, como por ejemplo, que en diciembre comienza el verano, que la correspondencia tarda más que en otras épocas, que solo un mes antes Neruda había legalizado su matrimonio con Matilde, que podría encontrarse en cualquiera de sus casas o en cualquier lugar de Chile, sin ninguna posibilidad de recibir su correspondencia.

Para Neruda, ayudarle a realizar su proyecto fue un acto de generosidad muy propio de él como tantos otros realizados durante su vida, pero para Rogovin, realizar ese trabajo en colaboración con Neruda era un golpe de gracia para su trabajo artístico, de modo que deseaba realizarlo cuanto antes.

Lo anterior queda demostrado en que apenas recibida la carta en la que Neruda le sugiere fijar la fecha del viaje, ya sea el verano de 1967 o el de 1968, Rogovin le escribe a Nemesio Antúnez, por esos días, Agregado Cultural de Chile en las Naciones Unidas, informándole que "Su distinguido poeta, el señor Pablo Neruda, me ha invitado a trabajar dos meses en colaboración con él". Y, luego, agrega: "El señor Neruda me ha comentado que está eligiendo el área donde trabajaremos por unos pocos meses" (Trujillo, 2013, p. 186).

En los días siguientes el entusiasmo del fotógrafo sigue creciendo en relación con su proyecto y, según lo que se lee en su carta del 10 de diciembre de 1966, al consulado chileno, el entusiasmo lo lleva a confundir el ofrecimiento de ayuda con una propuesta del poeta para realizar un trabajo con él.

Caballeros:

Con gran alegría estoy contando los días para visitar su país en enero y febrero. Recientemente su distinguido poeta Pablo Neruda me invitó a trabajar con él en un proyecto fotográfico en la isla de Chiloé.

El apresuramiento y la urgencia para conseguir su objetivo hacen que Rogovin cometa muchísimos errores. Como era de esperar, Neruda no recibió la carta a tiempo, de modo que, empujado por la preocupación y la posibilidad de que el viaje no resulte, el fotógrafo le envía el siguiente mensaje vía Western Union, el $1^{\circ}$ de enero de 1967, a las 6:41 p.m.:

\section{Querido amigo:}

En su carta del 13 de noviembre usted menciona que enero y febrero son adecuados para trabajar en Chiloé. No he recibido respuesta ni a mi telegrama ni a la carta acordando ir a Chile el 15 de enero. Tengo pasaporte, vacuna, boleto de avión y

\footnotetext{
${ }^{3}$ Ciertamente no era que "la mayoría de los aviones" volaran a Santiago sino que todos los vuelos internacionales llegaban allí. Por otro lado, en Valparaíso no había ni hay ningún aeropuerto.

${ }^{4}$ Los destacados son míos.
} 
material fotográfico. Por favor, déjeme saber por telegrama o llamada de cobro revertido si su invitación todavía se mantiene. Que pase un Feliz Año Nuevo. Ansioso de trabajar con usted por cualquier cantidad de tiempo que tenga disponible.

Finalmente, el viaje se realizó; Neruda consiguió que algunos de sus amigos lo recibieran en Santiago, le presentaran a otros amigos allí, y luego lo llevaran a Isla Negra. Lo invitó a quedarse en su casa; le presentó a la escultora María Martner, quien lo llevaría a Valparaíso unos días después. De Santiago, viaja por avión a Puerto Montt donde lo recibe Rodrigo Azócar, hijo del novelista Rubén Azócar y, por tanto, sobrino de Albertina, una de las musas de Veinte poemas de amor y una canción desesperada. De allí seguirá a Chiloé, donde será recibido por Luisa Chijani, a quien llega con una carta del poeta, y luego viajará a Quemchi, donde lo recibirán otros amigos suyos.

Su regreso a Santiago y posterior viaje a Lima, Perú, serán igualmente coordinados y amparados por amigos de Neruda. Tras abandonar Chiloé, en Puerto Montt es ayudado por una hermana de Rodrigo Azócar; en Santiago se encontrará una vez más con Alejandro Lipschütz, Acario Cotapos y Homero Arce, y este último le entregará una carta que Neruda le dejó para el escritor y político peruano Esteban Pavletich Trujillo quien debería recibirlo y servirle de guía durante su paso por Lima.

\section{CONCLUSIÓN}

En síntesis, la proverbial generosidad de Neruda fue una virtud que lo acompañó a lo largo de toda su vida. Amigo de sus amigos, estuvo siempre al lado de ellos defendiéndolos, promoviéndolos y apoyándolos cada vez que fuera necesario. Fue un poeta generoso como pocos a la hora de cumplir con la tarea de escribir una reseña, un prólogo o hacer de presentador de un colega. No mezquinó su palabra ni su apoyo y, seguramente, por la misma razón, más de alguna vez debe haberse equivocado en algunos de sus juicios. Pero de lo que no hay ninguna duda es de que su generosidad con los demás artistas, incluso artistas que apenas conocía, no solo lo llevó a comprometer la ayuda propia sino, como hemos visto en el caso del fotógrafo norteamericano, la de una vasta red de contactos a lo largo de su país y del extranjero puesta generosamente a su servicio con el objeto de ayudarle a cumplir de la mejor manera su propósito.

\section{Villanova University* \\ Department of Romance Languages and Literatures Villanova University Villanova, PA 19085 (USA) carlos.trujillo@villanova.edu}

Una primera versión de este artículo fue leído en el Congreso Internacional de la Asociación de Estudios Latinoamericanos (LASA), Washington DC, Mayo 30, 2013. 


\section{Carlos Trujillo}

\section{OBRAS CITADAS}

Gautier, Dominique y Ortiz, Jean (2011). "La travesía solidaria: Un documental sobre Neruda y el Winnipeg". Rebelión. Rescatado el 16 de noviembre de 2011. Disponible en: http://www.rebelion.org/noticia.php?id=139348

Neruda, Pablo. (2004). The House in the Sand. Prose Poems by Pablo Neruda and photographs by Milton Rogovin. Translated by Dennis Maloney \& Clark M. Zlotchew. Buffalo: White Pine Press.

— (2002). Obras Completas. Vol. V. Nerudiana dispersa II, 1922-1973. Edición prólogo y notas de Hernán Loyola. Barcelona: Galaxia Gutenberg-Círculo de Lectores. $1^{a}$ Edición,.

_ (2001a). Obras Completas. Vol. II. De 'Odas elementales' a 'Memorial de Isla Negra', 1954-1964, Edición prólogo y notas de Hernán Loyola. Barcelona: Galaxia Gutenberg-Círculo de Lectores. $1^{\text {a }}$ Edición.

— (2001b). Obras Completas. Vol. IV. Nerudiana dispersa I, 1915-1964. Edición prólogo y notas de Hernán Loyola. Barcelona: Galaxia Gutenberg-Círculo de Lectores, Primera edición,

Neruda, Pablo y Milton Rogovin. (1998). Neruda at Isla Negra. Edited by Dennis Maloney. Translated by Maria Jacketti, Dennis Maloney, and Clark Zlotchew. Fredonia: White Pine Press.

Rogovin Milton. (s/f). Autobiografia. Manuscrito inédito.

Rogovin, Milton y Pablo Neruda. (1999). Windows That Open Inward: Images of Chile. Poems by Pablo Neruda. Photographs by Milton Rogovin. Edited by Dennis Maloney. Buffalo: White Pine Press.

Rogovin, Milton y Carlos Trujillo. (2007). Nada queda atrás. Santiago: MAM Chiloé/Editorial Isla Grande.

Rovira Soler, José Carlos. "Neruda: el tiempo español de la solidaridad y el compromiso". Disponible en: http://www.cervantesvirtual.com/obra-visor/neruda--el-tiempoespaol-de-la-solidaridad-y-el-compromiso-0/html/000ab534-82b2-11df-acc7002185ce6064_2.html\#I_1_

Trujillo, Carlos. (2013). Si no fuera por la lluvia. Milton Rogovin en Chile. Concepción: Editorial Okeldan. 